\title{
Presenting a Structural Equation Model for Effects of Auditor Independence on Audit Quality from Managers' Perspective of Companies in Tehran Stock Exchange
}

\author{
Assistant Professor Mohammad Ali Aghaei \\ Faculty of Management \& Economics, Tarbiat Modares University, Tehran, Iran \\ aghaeim@modares.ac.ir \\ Iman Ranjbar \\ Faculty of accounting, Islamic Azad University of Bushehr, Bushehr, Iran \\ ranjbareiman@yahoo.com
}

\section{Doi:10.5901/mjss.2016.v7n2s2p78}

\section{Abstract}

Audit through validating the financial statements, reduces information asymmetry which exist between managers and shareholders. Due to two reason expected, there is a positive relationship between the amount of discretionary accruals and the inherent risks of accounting. First, assuming managerial opportunism, accruals is a tool of management to manage reported earnings and managers manipulate accruals to their advantage second, accruals, which are difficult to audit associated with most risk accounts such receivable and inventories. It is thought that the level of audit quality is confirmed by the economic environment, it is vital to the continuation of a long-term auditing and the future of the audit profession has considerable depends on quality of output audit process. Therefore, in this study we have tried to provide a structural equation model to examine the effect of auditor independence on audit quality. After the initial questionnaire was distributed and confirmed the validity and reliability of standardized research, the standard deviation of the results of the questionnaire showed that most of the population standard deviation is equal to 0.318 . Thus, according to the obtained standard deviation, maximum sample size is estimated at 5\% error level is equal to 95 after the 130 questionnaires distributed, 107 completed questionnaires were collected. Thus, the statistical analysis in this study was based on 107 questionnaires. Structural equation modeling, the method has been used to design the research model. By comparing the values of obtained fitness criteria with acceptable range, the results showed that all the parameters values were deemed desirable. So the final version was approved and the main hypothesis that the impact of auditor's independence on audit quality is approved. As the impact of that in the nonstandard mode is equal to 0.58 and in the standard mode is equal to 0.32 .

Keywords: auditor's independence, audit quality, Tehran Stock Exchange

\section{Introduction}

There are some circumstances in the reporting process, allowing direct assessment of data quality by users become very difficult. Demand for audit in reporting process under conditions of conflict of interest, with important economic implications, the complexity of economic activity and the lack of direct access can be justified. Conflicts of interest between two group of producers and users of information, is the best the justification for the need to audit and in this case, is one of the main reasons for the need for an independent audit (Norosh and Ramazani, 2010). Independence is the essence and spirit of audit and non-independence audit is no value or meaning. Independence in Webster dictionary (1986) is defined as free from influence, control, or the will of another or others. De Angelo (1981) states an independent audit must release accounting records in accordance with the opinion of its actual (quoting Abrahami Mand and Sajjadi, 2005).

Financial statements audited by independent auditors are the suitable device for transfer reliable data. Independent auditor is the most qualified person to comment on the reliability of financial reporting and economic unit. Auditor competency that is why he is an independent audit in accordance with auditing standards to ensure that the items of financial statements in accordance with accounting standards have been prepared. Therefore, the auditor to validate claims that the financial statements have been prepared by someone else and thereby increase the reliability of the data used in economic decisions (Nikkhah Azad, 2000).

In the real world, received and cash payments made in the course occurs which is usually caused by the different timing of the transactions and events and this leads to the use of accruals (assuming the obligation) to measure the 
performance of business units, net of cash receipts to be much better. But the problem is that unlike the accrual of cash flow associated with a degree of ambiguity which reduces the reliability of them (Muhammad Zadegan, 2006). But in the meantime, the issue of conflict of interest between ownership and management, accruals presented in the financial statements can be manipulated by managers and they questioned the reliability (Crasewell et al, 2002). Based on the discussions, the question is how can support investors to manipulate items in the financial statements? One of the most effective ways to control manipulation of accruals by management and applied the management's comments in the selection of accounting practices is audit process (Abrahimi Kordlar, 2008). Generally accepted auditing standards, the financial statements are described as presentation of management. Since managers are also part of the interest groups is likely provided that they are biased (Shane, 1994).

Therefore, auditors will act as observers who are trying to reduce this bias. Managers had considerable influence on recruitment, retention and change their auditors. Managers, are able to take advantage of this select auditors commented that the desired order of management thereby maximize its benefits (Lennox, 1998). This management effect leads to erosion of audit quality and create factors which may lead to failure of the audit. Thus, this study will attempt to assess the impact of auditor independence and review audit quality so that we offer appropriate solutions in this area.

\section{Research Methodology}

Since this research in a real organization, taken objective and dynamic and the results can be use practically, is an applied research. On the other hand, descriptive method is used in most social science research. Descriptive study includes a set of techniques that aim to characterize the study population.

With the implementation of this research can be more understanding of the current situation and it can be used in the decision-making process. So with regard to the foregoing, it can be said that the present study, a research descriptive I analysis is of survey research. Data collection method in this study was a questionnaire. Most comprehensive questionnaire on paper in the field of auditor independence is extracted from (Sajjadi, Abrahimi Mand, 2005) is classified in three basic dimensions (competition among audit firms for customer acceptance, the client audit committee, size and duration of the audit firm) is classified and its indices are as follows. It should be noted fourth dimension of the questionnaire due to failing to convert it to a questionnaire has been removed.

\begin{tabular}{|l|l|}
\hline Competition among audit firms to accept client & $\begin{array}{l}\text { Competition among auditors to provide services at lower prices } \\
\text { Competition among auditors to provide more services and more diverse } \\
\text { Competition in general }\end{array}$ \\
\hline Audit committee for work & $\begin{array}{l}\text { Adequate financial knowledge of the audit committee client } \\
\text { Knowledge, experience and competencies independent audit by the audit committee } \\
\text { Hours of Operation Director and senior member of the audit firm to evaluate and } \\
\text { compare the time the budget by the audit committee } \\
\text { The ceiling for non-audit services to audit local }\end{array}$ \\
& $\begin{array}{l}\text { A key role in the selection or change of auditor } \\
\text { A key role in determining the remuneration of the auditor } \\
\text { Internal auditors and independent proposals }\end{array}$ \\
\hline Size and duration of the audit firm & $\begin{array}{l}\text { Having more than 5 partners with more than } 15 \text { years } \\
\text { Having more than } 10 \text { partners with more than 10 years } \\
\text { Having more than 50 partners with more than 25 years } \\
\text { Having more than 3 partners with more than 20 years }\end{array}$ \\
\hline
\end{tabular}

Also factor of audit quality is classified in the following seven dimensions:

- Environmental factors such as government laws and regulations.

- Outputs such as audit reports and audit information.

- Auditor's reputation

- Expectations of auditors

- Communication and interaction of auditor

- Audit risk management strategies

- $\quad$ Audit fees paid

The research population includes of managers available senior and middle of companies that constitute the Tehran Stock Exchange at the time of the study were about 243 people. In this study due to lack of access to all the directors sampling method in the finite population was used. 


$$
n=\frac{N \times Z_{\%}^{2} \times \delta^{2}}{\varepsilon^{2}(N-1)+Z_{\alpha / 2}^{2} \times \delta^{2}} \quad \Rightarrow \quad n=\frac{243 \times(1.96)^{2} \times 0.318^{2}}{0.05^{2}(242)+(1.96)^{2} \times 0.318^{2}}=95
$$

A preliminary sampling was used to determine the standard deviation of the population. For this purpose, a questionnaire survey was distributed randomly among the 34 members of the community managers. The results of the standard deviation of the questionnaire question showed that most of the population's standard deviation is equal to 0.318. Thus, according to the obtained standard deviation, maximum sample error of 5\%, which is equivalent to 95 after the 130 questionnaires distributed, 107 completed questionnaires were collected. Thus, the statistical analysis in this study was based on 107 questionnaires. To analyze the data after the initial research model, structural equation using the Amos software is used. Initial research model is similar to the figure below.

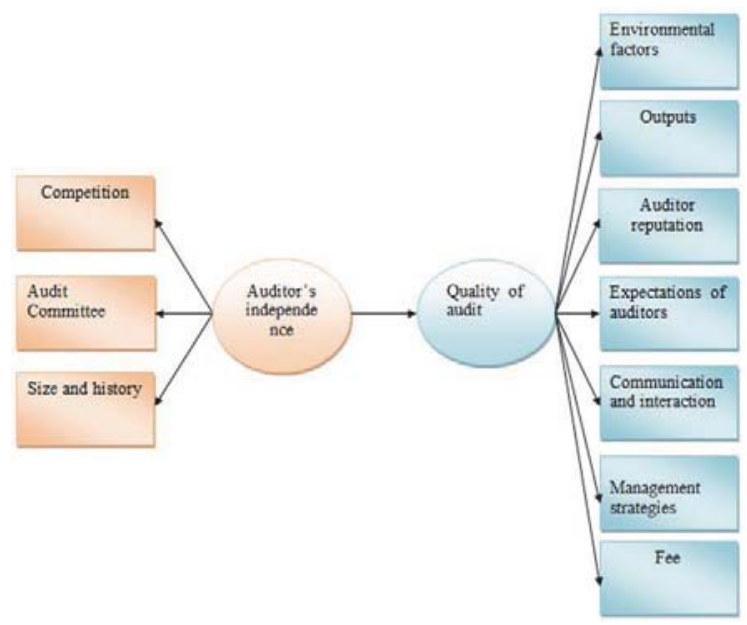

Figure 1: The conceptual model

Structural equations of new statistical methods are one of the most powerful methods of multivariate analysis. Its main application is in the multivariate subjects which could not be in the way of bi variable by taking each time an independent variable with the dependent variable. Multivariate analysis refers to a method of analysis that their main features are analysis and multiple independent variables with dependent variables (Homan, 2005). Structural equations as a statistical model to examine the relationships between variables, latent and manifest (observed) and generally said Structural Equation Modeling or SEM, but some referred it the covariance structure analysis, or casual and LISREL modeling.

Through structural equation can be confirmed general or hypothetical constructs causal patterns with nonexperimental data. Structural equation provides coherent framework to assess the strength of relationships between all variables of a theoretical model. Theories are based on this model are essential and without them there would not be an apt description of the relationships of variables. Multiple regression analysis is a family of multivariate structural equation which allows the simultaneous analysis provides a set of regression equations. In fact, the structural equation modeling is a comprehensive statistical approach to test assumptions about the relationship between observed and latent variables. In the structural equation model approach is as follows:

1. Set up a model based on a theory, pattern or model, a statistical statement about the relationships between variables. These patterns of different analytical approaches are in various forms. For example, a model of correlation is significant to shows the bilateral relations between the two variables; while show multiple regression and analysis of variance models with directional relationships between variables. The model is based on a model or a theory of structural equation or mathematical expression is produced. The first way draws a diagram and the relationships between variables. After identifying the hidden variables should select appropriate indicators or variables observed and connect to it. It is better than one index instead of an index used to measure the latent variable and this is done by defining the concept and operation (Homan, 2005).

2. Determine the assessment of model or template: under these conditions, the model should be required to obtain a unique solution for the parameters stated. 
3. Estimates for the proposed model: Get the free parameters estimated from the total count data including repetitive processes, iterations of a covariance matrix implied is made covariance matrix is compared with the observed data. Compare the two matrices yields a residual matrix and the iterations continue until the residual matrix to minimize.

4. Assess the suitability or fitness of the model or models: the model or models fit the observed data and the covariance matrix implied by the observed data covariance matrix is equivalent. This means that the matrix is close to zero. The most important step in this phase is: Evaluation criteria for the assessment of overall model fit and the ability to test whether reform is needed or not? When the model is estimated, a set of software and other statistics such as the standard error on the evaluation of the model fit to the data releases.

5. Correction model: adapting model parameters are estimated by unlocking previously been fixed or fix the parameters that have been released before.

6. Translation: If fitness tests show that the model adequately fits the data, at this stage, we focus on specific factors (model parameters) model fits our focus. At this stage, the significant parameters of the model are evaluated. Both reliability and validity of the questionnaire using Cronbach's alpha. KMO and Bartlett's test was confirmed as follows.

Table 1: Cronbach's alpha coefficient to measure the reliability of research

\begin{tabular}{|l|c|c|}
\hline Index & Cronbach's Alpha & N of Items \\
\hline Auditor's independence & .821 & 15 \\
\hline Quality of audit & .708 & 26 \\
\hline
\end{tabular}

Table 2: KMO and Bartlett factor for assessing the validity of the research

\begin{tabular}{|l|c|c|}
\hline Index & KMO \& Bartlett's Coefficient & Sig \\
\hline Auditor's independence & .746 & 0.000 \\
\hline Quality of audit & .792 & 0.000 \\
\hline
\end{tabular}

\section{The Findings}

Before carrying out any statistical analysis, it is essential to normal or non-normal distribution of data to ensure. To do this we must use the Kolmogorov-Smirnov test. According to the table below and in accordance with the significance level that is higher than $\mathbf{0 . 0 5}$, auditor independence is normally distributed data in the questionnaire and continue to do parametric tests for data use.

Table 1: Kolmogorov-Smirnov test for auditor independence questionnaire

\section{One-Sample Kolmogorov-Smirnov Test}

\begin{tabular}{|ll|c|}
\hline & & Importance Data \\
\hline $\mathrm{N}$ & & 107 \\
Normal Parameters & & 5.1719 \\
& Mean & 1.33492 \\
& Std. Deviation & .224 \\
Most Extreme Differences & Absolute & .117 \\
& Positive & -.224 \\
Kolmogorov-Smirnov Z & Negative & 1.268 \\
Asymp. Sig. (2-tailed) & & .079 \\
\hline
\end{tabular}

a. Test distribution is Normal.

In this section, the results of data analysis for each of the three dimensions of the auditor independence to the extent of competition among audit firms for customer acceptance, the client audit committee, the size of the firm will express an 
audit. The following table shows the mean and standard deviation of dimensions.

Table 2: Mean and standard deviation of dimension state of the auditor independence

\begin{tabular}{|c|c|c|c|c|}
\hline & $\mathrm{N}$ & Mean & Std. Deviation & Std. Error Mean \\
\hline VAR00001 & 107 & 3.2031 & 1.34919 & .23851 \\
VAR00002 & 107 & 3.5380 & 1.23857 & .21895 \\
VAR00003 & 107 & 4.8958 & 1.42290 & .25154 \\
\hline
\end{tabular}

In the first part, the results of data analysis using student T-test and one-way design is based on the assumption will be examined. Because the questionnaire was based on the range of 7 options, according to statistical books should mean to be harsh, consider the number 4.

Secondary-Hypothesis 1: After competition between the audit firms from managers' perspective, the stock is in good condition.

To investigate this hypothesis, statistical hypothesis was designed as follows.

After competition between the audit firms from managers' perspective of stock, it is not in good condition. $H_{0}: \mu \leq 4$

After competition between the audit firms from managers' perspective of stock, it is in good condition. $H_{1}: \mu>4$

Table 3: Results derived from secondary hypothesis 1

\begin{tabular}{|c|c|c|c|c|c|c|}
\hline & \multicolumn{9}{|c|}{ One-Sample Test } \\
\cline { 5 - 7 } & $\mathrm{t}$ & $\mathrm{df}$ & Sig. (2-tailed) & \multirow{2}{*}{ Mean Difference } & \multicolumn{2}{|c|}{ 95\% Confidence Interval of the Difference } \\
\cline { 5 - 7 } & & & & Lower & Upper \\
\hline VAR00001 & -5.044 & 106 & .067 & -1.20312 & -.7167 & -1.6896 \\
\hline
\end{tabular}

As the above table shows the results at $95 \%$ the null hypothesis is rejected and alternative hypothesis approved. This means that the competition among audit firms to accept client is not in good condition. It should be noted that the above analysis should be considered a significant level, as well as up and down. In the analysis Lower and upper in the table should be based on the following descriptions:

1. When both limit is low and high positive, mean is greater than the value of the test (the test case in this study, number 4).

2. If both the lower and upper limit is negative, the test is smaller than average.

3. If the lower limit and the upper limit are positive, negative, with a mean value of the test is not significant.

Statistical Analysis of other dimension is also in the following tables. condition.

Subsidiary-Hypothesis 2: The dimension of audit committee from managers' perspective of stock firms is in good

To investigate this hypothesis, statistical hypothesis was designed as follows.

The dimension of audit committee from managers' perspective of stock firms is not in good condition. $H_{0}: \mu \leq 4$ The dimension of audit committee from managers' perspective of stock firms is in good condition. $H_{1}: \mu>4$

Table 4: Results derived from hypothesis 2

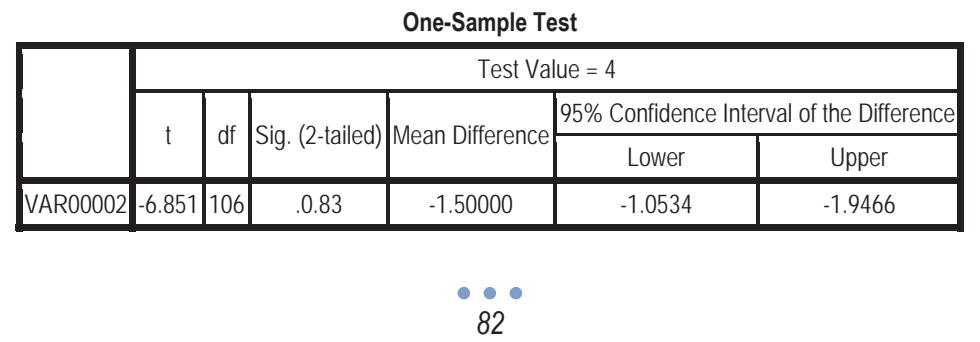


As the above table shows the results at $95 \%$ the null hypothesis is rejected and alternative hypothesis approved. This means that the existence of an audit committee is not in good condition.

Subsidiary-Hypothesis 3: The dimension of the size and history of the audit firm from managers' perspective of stock firm is in good condition.

To investigate this hypothesis, statistical hypothesis was designed as follows.

The dimension of the size and history of the audit firm from managers' perspective of stock firm is not in good condition. $H_{0}: \mu \leq 4$

The dimension of the size and history of the audit firm from managers' perspective of stock firm is in good condition. $H_{1}: \mu>4$

Table 5: Results derived from subsidiary hypothesis 3

\begin{tabular}{|c|c|c|c|c|c|c|}
\hline \multicolumn{7}{|c|}{ One-Sample Test } \\
\hline & \multicolumn{6}{|c|}{ Test Value $=4$} \\
\hline & \multirow{2}{*}{$\mathrm{t}$} & \multirow{2}{*}{ df } & \multirow{2}{*}{ Sig. (2-tailed) } & \multirow{2}{*}{ Mean Difference } & \multicolumn{2}{|c|}{$95 \%$ Confidence Interval of the Difference } \\
\hline & & & & & Lower & Upper \\
\hline VAR00003 & 4.698 & 106 & .000 & 1.26562 & .7162 & 1.8151 \\
\hline
\end{tabular}

As the above table shows the results at $95 \%$ the null hypothesis is rejected and alternative hypothesis approved. This means that the size and history of the audit firm is in good condition. As seen best in this part of the audit quality be measured found to be more accurate conclusions.

Since the re-distribution of the data in this section is also normal, T-test student will be done in order for the seven dimensions.

Table 6: Results derived from the dimensions of audit quality questionnaire

One-Sample Test

\begin{tabular}{|l|c|c|c|c|c|c|}
\hline \multirow{2}{*}{ Dimension } & \multicolumn{9}{|c|}{ Test Value = 4 } \\
\cline { 2 - 4 } & \multirow{2}{*}{$\mathrm{t}$} & $\mathrm{df}$ & Sig. (2-tailed) & Mean Difference & \multicolumn{2}{|c|}{ 95\% Confidence Interval of the Difference } \\
\cline { 6 - 8 } & & & & & Lower & Upper \\
\hline Environmental factors & 2.347 & 106 & .000 & .21158 & .3896 & .0335 \\
Outputs & -2.017 & 106 & .094 & -.18669 & -.3696 & -.0038 \\
Auditor's reputation & .141 & 106 & .000 & .01391 & -.2087 & .1809 \\
Expectations of auditors & -.472 & 106 & .204 & -.04257 & -.2209 & -.1357 \\
Communication and interaction & -1.601 & 106 & .056 & -.16667 & -.3724 & -.0391 \\
Management strategies & 2.443 & 106 & .000 & .25974 & .0497 & .4697 \\
Fee & 1.274 & 106 & .000 & .14935 & .0822 & .3809 \\
\hline General situation & 1.439 & 106 & .007 & .20081 & .1139 & .2097 \\
\hline
\end{tabular}

In the above table, the dimension which has a significance level of less than 0.05 are in good condition four categories located in this category and output dimensions, expectations of auditors and communication and interaction have been in the unsuitable situation where this can occur due to lack of auditor independence. So at this stage, to prove the factors influencing auditor independence, can affect the quality of the audit. To investigate the value of model structural equation was used with help Amos software. The results of the fitting the model in the form of standard and non-standard coefficients was shown in Figures 2 and 3. 


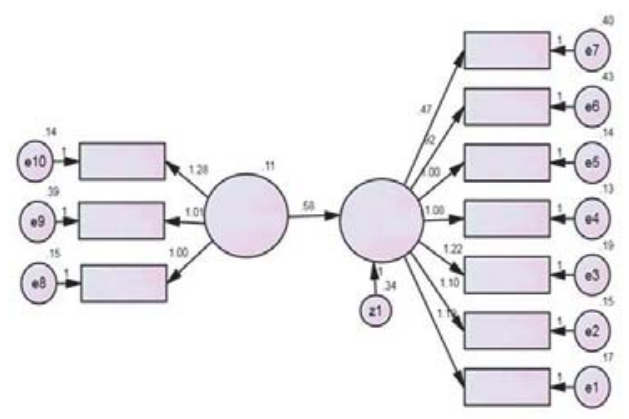

Figure 2: Nonstandard coefficients of research model

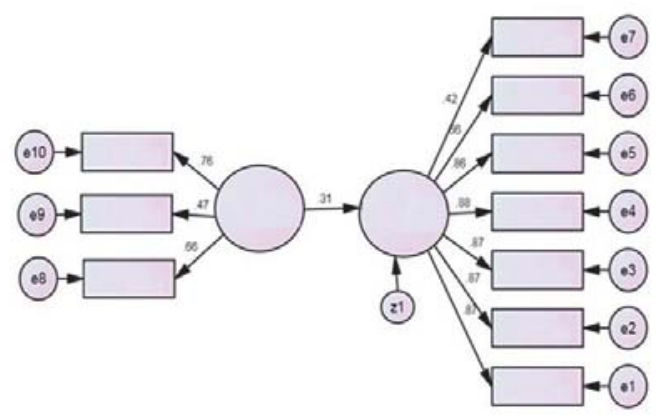

Figure 3: Standard coefficients of research model

The results of the study showed significant path coefficients in the model estimated in Table (7) are shown.

Table 7: Significant path coefficients

\begin{tabular}{|c|c|c|c|c|c|c|}
\hline & & & Estimate & S.E. & C.R. & $P$ \\
\hline Quality of audit & $<---$ & Auditor's independence & .584 & .161 & 3.617 & 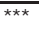 \\
\hline Environmental factors & $<--$ & Quality of audit & 1.000 & & & \\
\hline Outputs & $<--$ & Quality of audit & 1.080 & .061 & 17.617 & *** \\
\hline Auditor's reputation & $<--$ & Quality of audit & 1.220 & .071 & 17.187 & *** \\
\hline Expectations of auditors & $<--$ & Quality of audit & 1.102 & .064 & 17.184 & 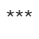 \\
\hline Communication and interaction & $<--$ & Quality of audit & 1.190 & .068 & 17.410 & *** \\
\hline Management strategies & $<--$ & Quality of audit & .922 & .083 & 11.132 & *** \\
\hline Fee & $<--$ & Quality of audit & .475 & .074 & 6.448 & 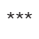 \\
\hline Competition & $<--$ & Auditor's independence & 1.000 & & & \\
\hline Audit Committee & $<--$ & Auditor's independence & 1.013 & .192 & 5.267 & *** \\
\hline Size and history & $<--$ & Auditor's independence & 1.280 & .232 & 5.523 & $\star \star * *$ \\
\hline
\end{tabular}

As the above table shows the results of all the estimated path coefficients are significant. On the one hand fitting the model indices suggest that the RMSEA value is equal to 0.138 and more than 0.1 . So the amendments proposed by the software, the model was re-dissolved.

The results of the model in the form of correction coefficients, standard and nonstandard forms are shown in figures 4 and 5 . 


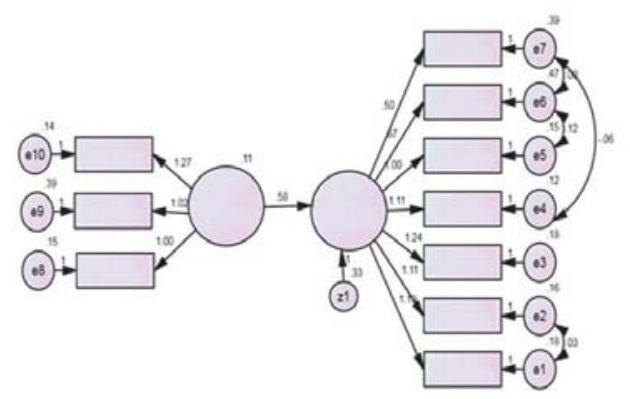

Figure 4: Nonstandard coefficients of research correction model

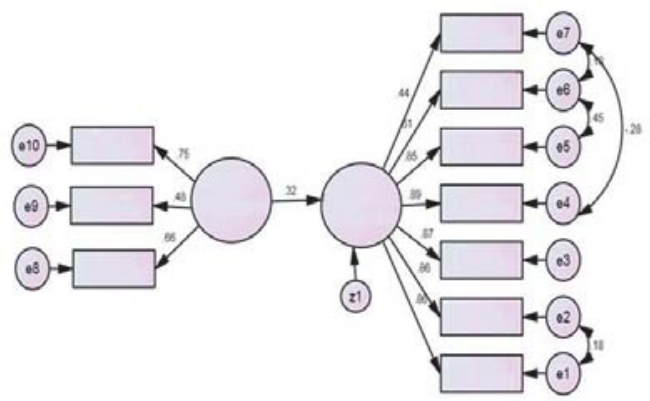

Figure 5: Standard coefficients of research correction model

The meaningful calculated results of research correction model are shown in the table (8).

Table 8: Significant path coefficient of correction model

\begin{tabular}{|c|c|c|c|c|c|c|}
\hline & & & Estimate & S.E. & C.R. & $\mathrm{P}$ \\
\hline Quality of audit & $<-\ldots$ & Auditor's independence & .581 & .160 & 3.631 & $* * *$ \\
\hline Environmental factors & <-- & Quality of audit & 1.000 & & & \\
\hline Outputs & $<--$ & Quality of audit & 1.109 & .063 & 17.472 & $* \star * \star$ \\
\hline Auditor's reputation & $<--$ & Quality of audit & 1.237 & .074 & 16.761 & *** \\
\hline Expectations of auditors & $<--$ & Quality of audit & 1.109 & .067 & 16.429 & $* \star \star$ \\
\hline Communication and interaction & $<--$ & Quality of audit & 1.191 & .072 & 16.491 & *** \\
\hline Management strategies & <-- & Quality of audit & .873 & .070 & 12.415 & *** \\
\hline Fee & $<---$ & Quality of audit & .503 & .075 & 6.673 & *** \\
\hline Competition & $<--$ & Auditor's independence & 1.000 & & & \\
\hline Audit Committee & <-- & Auditor's independence & 1.019 & .193 & 5.285 & *** \\
\hline Size and history & $<--$ & Auditor's independence & 1.275 & .230 & 5.541 & *** \\
\hline
\end{tabular}

As the above table shows all the estimated path coefficients are significant. The research model fit indexes in the table (9) is shown. By comparison fitness values with the acceptable range, the all indicators were deemed to be acknowledged values. Thus, the final version is approved. The main hypothesis about the impact of auditor independence on audit quality is approved. As the impact is positive and in non- standard state is equal to 0.58 and in standard mode is equal to 0.32 . 
Table 9: Fitness indicators of research corrective model

\begin{tabular}{|l|l|l|l|l|l|l|l|}
\hline Fitness Index & $x^{2} / d f$ & RMSEA & GFI & IFI & TLI & NFI & CFI \\
\hline Accepted range & $\prec 5$ & $\prec 0.1$ & $\succ 0.9$ & $\succ 0.9$ & $\succ 0.9$ & $\succ 0.9$ & $\succ 0.9$ \\
\hline Results & 2.691 & 0.078 & 0.928 & 0.953 & 0.934 & 0.938 & 0.951 \\
\hline
\end{tabular}

\section{Conclusion}

As you can see, the factors affecting the independence of the audit could have more roles in enhanced or reduced audit quality. Institute of Management Accountants, UK (2001) argues that the role of the audit committee of the company is much more than interface of company and auditor and emphasizes that the audit committee should have a key role in the selection of independent auditors (Sajadi, Abrahimi Mand, 2005).

Large companies usually have stronger internal control mechanisms and try to choose higher quality auditors. Irene Asklayf Research Institute (2000), in a report presented to the committee independence standards regarding the size of the client company and the independent auditor says: For participants, the possibility of misuse of subjects equal for both large corporations and small companies were claiming. Larger companies have a strong system of internal control and reporting high quality. On the other hand, due to higher audit fees, auditors and audit firms try to obtain at any price.

Although smaller firms with low audit fee and the audit may be simpler. The company's auditors try to have a friendly relationship with the client. Therefore, the size (large or small) can lead to increased independence of audit firms and a decrease in the auditor's independence.

Great audit institutions of higher reputation and usually costs more to train their own auditors and quality control are stronger. Dopuch and Simunic (1980) speculating big audit firms to enhance the quality of their audit, they invest a lot (Dopuch, N. And D. Simunic, 1980). Several studies conducted in other countries have shown that there was a significant positive relationship between the size of the audit firm and auditor independence. The study also found that the size of the client company has a large impact on audit quality. It is recommended that the Tehran Stock Exchange, institutions and organizations such as the Industrial Development and Renovation Organization of Iran are responsible owned manufacturing and service companies with necessary measures, select auditing firms in accordance with the size of audit firms and company's audit committee are required to have adequate supervision on the audit process of companies.

\section{References}

Crasewell, A., D. Stokes and J . Laughton, (2002). "Auditor Independence and fee Dependence" Journal of Accounting and Economics. $33(253-275)$.

Dopuch ,N. and D. Simunic, (1980), "The Nature of compettion in the Auditing Profession: Adescriptive and Nomative View ".The lllinois Auditing Symposium.

Ebrahimi Kordlar, Seyedi and Ali, Syed Aziz (2008). "The role of independent auditors on decreasing discretionary accruals". Survey of Accounting and Auditing, Volume 15, Number 54, 2008, pp. 16-3.

Hooman, Heidar Ali (2005). Structural equation modeling with LISREL software application. Tehran: the side.

Nikkhah Azad, A., (translator) (2000), "Fundamental concepts of auditing". Accounting Guidelines Committee, Tehran: National Audit Office, 121.

Norosh, Iraj. and Ramezani Masoud (2010). Factors affecting auditor independence and audit services from the perspective of independent auditors and users of financial accounting, Volume 2, Issue 7, pp. 22-1.

Sajjadi, Seyyed Hossein Ebrahimi Vand, M (2005). Increasing the independence of the independent auditor, review of accounting and auditing, Year XII, No. 40, pp. 80-61. 